\title{
Potent anti-leukemic activity of a specific cyclin-dependent kinase 9 inhibitor in mouse models of chronic Iymphocytic leukemia
}

\author{
Joachim R. Göthert ${ }^{1}$, Roze Imsak ${ }^{1}$, Michael Möllmann ${ }^{1}$, Stefanie Kesper ${ }^{1}$, \\ Maria Göbel ${ }^{1}$, Ulrich Dührsen ${ }^{1}$, Arne Scholz ${ }^{2}$, Ulrich Lücking ${ }^{2}$, Matthias Baumann ${ }^{3}$, \\ Anke Unger ${ }^{3}$, Carsten Schultz-Fademrecht ${ }^{3}$, Bert KlebI ${ }^{3}$, Jan Eickhoff ${ }^{3}$, Axel Choidas ${ }^{3}$ \\ and Jan Dürig ${ }^{1}$ \\ ${ }^{1}$ Department of Hematology, West German Cancer Center (WTZ), University Hospital Essen, Essen, Germany \\ ${ }^{2}$ Bayer AG, Pharmaceuticals, Drug Discovery, Berlin, Germany \\ ${ }^{3}$ Lead Discovery Center GmbH (LDC), Dortmund, Germany \\ Correspondence to: Joachim R. Göthert, email: joachim.goethert@uk-essen.de \\ Keywords: chronic lymphocytic leukemia; cyclin-dependent kinase 9; MEC-1 cell line; TCL1 transgenic mice; NSG mice \\ Received: August 16, $2017 \quad$ Accepted: April 07, $2018 \quad$ Published: May 29, 2018 \\ Copyright: Göthert et al. This is an open-access article distributed under the terms of the Creative Commons Attribution License \\ 3.0 (CC BY 3.0), which permits unrestricted use, distribution, and reproduction in any medium, provided the original author and \\ source are credited.
}

\section{ABSTRACT}

Onset of progression even during therapy with novel drugs remains an issue in chronic lymphocytic leukemia (CLL). Thus, there is ongoing demand for novel agents. Approaches targeting cyclin-dependent kinases (CDK) have reached the clinical trial stage. CDK9 mediating RNA transcriptional elongation is the evolving pivotal CLL CDK inhibitor target. However, more CDK9 selective compounds are desirable. Here, we describe the CDK9 inhibitor LDC526 displaying a low nanomolar biochemical activity against CDK9 and an at least 50-fold selectivity against other CDKs. After demonstrating in vitro MEC-1 cell line and primary human CLL cell cytotoxicity we evaluated the LDC526 in vivo effect on human CLL cells transplanted into NOD/scid/ Yc null (NSG) mice. LDC526 administration $(75 \mathrm{mg} / \mathrm{kg}$ ) for 5 days resulted in a $77 \%$ reduction of human CLL cells in NSG spleens compared to carrier control treatment. Next, we longitudinally studied the LDC526 impact on circulating CLL cells in the TCL1 transgenic mouse model. LDC526 $(50 \mathrm{mg} / \mathrm{kg})$ administration for two days led to a 16-fold reduction of blood CLL cell numbers. Remarkably, residual CLL cells exhibited significantly increased intracellular BCL-2 levels. However, the LDC526 cytotoxic effect was not restricted to CLL cells as also declining numbers of normal B and T lymphocytes were observed in LDC526 treated TCL1 mice. Taken together, our in vivo data provide a strong rational for continued LDC526 development in CLL therapy and argue for the combination with BCL-2 inhibitors.

\section{INTRODUCTION}

CLL is the most common leukemia in Western countries [1]. The clinical course of CLL is highly variable. Specific biologic and clinical factors are associated with rapid progression towards more advanced disease stages in some patients whereas others survive for a long period without the need for treatment [2]. Compared to other hematologic malignancies CLL is a nonproliferative leukemia characterized by the over-expression of antiapoptotic BCL-2 family proteins [3]. Survival signals are provided by the highly specialized microenvironment of CLL [4-6]. It is possible to achieve minimal residual disease-negative CLL remissions with combination chemo-immunotherapy in a subset of patients [7], however the majority of patients will inevitably relapse. This will likely also hold true in the current era of novel anti-CLL drug approvals targeting Bruton's tyrosine kinase (BTK), phosphatidylinositol-3-kinase delta $(\mathrm{PI} 3 \mathrm{~K} \delta)$ and B-cell lymphoma/leukemia 2 (BCL-2) [8]. Patients treated 
with these novel agents still progress after treatment or may not tolerate them. Treatment failure with the novel agents may occur due to acquired resistance, which in the case of the BTK inhibitor ibrutinib was shown to be mediated by mutations in the ibrutinib-binding site of BTK [9]. Furthermore, patients also progress under treatment with the BCL-2 inhibitor venetoclax. It is assumed that venetoclax resistance is conferred by the overexpression of pro-survival proteins other than BCL-2 such as Myeloid cell leukemia 1 (MCL-1) [10-12]. Likely, a priori CLL dependence on MCL-1 rather than BCL-2 [13] conveys decreased venetoclax sensitivity in a subgroup of patients. Additionally, CLL MCL-1 expression is associated with the presence of poor prognostic markers and disease progression [14].

MCL-1 is a protein with a short half-life and its cellular levels are thus susceptible to transient inhibition of RNA transcription [15-17]. RNA transcription and in particular elongation are dependent on cyclin-dependent kinase 9 (CDK9) mediated serine phosphorylation of the RNA Polymerase II (RNAPII) carboxyterminal domain (CTD). CDK9 together with its cyclin partners ( $\mathrm{T}$ or $\mathrm{K}$ ) forms a functional complex termed positive transcription elongation factor $\mathrm{b}$ (pTEFb). The first generation CDK9 inhibitors such as SNS-032 or Alvocidip (flavopiridol) also targeting other cyclin-dependent kinases are capable of inducing apoptosis of CLL cells $[18,19]$. However, the clinical development of these compounds was negatively impacted by their side effect profile in particular by the occurrence of cytopenias, gastrointestinal symptoms and tumor lysis syndrome [20-22]. Likely, the combinatorial inhibition of multiple CDKs contributed to this side effect spectrum. The next-generation CDK inhibitor Dinaciclib specific for CDK1, CDK2, CDK5 and CDK9 was more efficient in inducing CLL apoptosis than flavopiridol $[23,24]$ and exhibited an improved safety profile $[25,26]$. Nonetheless, the occurrence of cytopenias was still reported in Dinaciclib clinical trials $[25,26]$.

To further increase CDK9 inhibitor specificity and to enable oral administration we developed the novel CDK9 inhibitor LDC526. A recent further pharmacologically optimization of LDC526 resulted in BAY1143572 [27], which has been studied in phase I trials in patients with acute leukemia and solid tumors / lymphomas (ClinicalTrials.gov, Identifier NCT02345382 and NCT01938638, respectively). Here, we report anti-CLL activity of LDC526 in the CLL-derived cell line MEC1 and in primary CLL cells. Moreover, we demonstrated effective anti-CLL activity of LDC526 in CLL xenografted NSG and TCL1 transgenic CLL mice. In these models LDC526 treatment also decreased non-malignant T cells, which represent an important component of the CLL microenvironment. High BCL-2 expression likely enabled a small fraction of CLL cells to escape LDC526-induced apoptosis.

\section{RESULTS}

\section{LDC526 inhibits survival of MEC-1 and primary CLL cells}

A program for the generation of specific CDK9 inhibitors resulted in the synthesis of the highly selective CDK9 inhibitor LDC526 (Figure 1A). Half-maximal inhibitory doses (IC50) for the CDK kinases 1/2/4/6/7 and 9 were determined. Versus CDK 9 LDC526 had a 52/82/291/>900/>900-fold selectivity compared to CDK2/1/4/6/7. In contrast, the other three compounds tested displayed a much lower CDK9 selectivity (e.g.: versus CDK9, Flavopiridol had a 3/2/13/49/16-fold selectivity compared to CDK2/1/4/6/7) (Figure 1B). Next, we performed in vitro selectivity kinase profiling with LDC526 using a panel of 219 recombinant kinases. More than $85 \%$ of tested kinases still displayed an activity of greater than $80 \%$ at a $1 \mu \mathrm{M}$ concentration of LDC526 (Figure 1C). Taken together, the functional in vitro kinase assays demonstrated CDK9 selectivity of LDC526.

As CDK9 inhibition should rapidly decrease levels of the prosurvival MCL-1 protein we studied apoptosis of the CLL-derived cell line MEC-1 after short-term LDC526 exposure (4 hours). Indeed, significantly increased MEC-1 apoptosis was observed at LDC526 concentrations of $500 \mathrm{nM}$ and more pronounced at 1 $\mu \mathrm{M}$ (Figure 1D, 1E). In parallel, we studied intracellular MCL-1 and BCL-2 expression on the single cell level using an intracellular flow cytometric assay (Figure 1F). In contrast to BCL-2, MCL-1 protein levels were reduced in the presence of increasing LDC526 concentrations (Figure 1F, 1G, 1H). Longer-term LDC526 exposure also induced apoptosis (Figure 1I) and decreased the number of viable MEC-1 cells at different concentrations (Figure 1J). To demonstrate that LDC526 primarily induces apoptosis rather than inhibiting proliferation we studied cell cycle progression by BrdU incorporation at different LDC526 concentrations (Figure 1K). In contrast to the impact on cell survival, LDC526 did not alter the cell cycle at concentrations up to $1 \mu \mathrm{M}$. Solely at very a high concentration such as $10 \mu \mathrm{M}$ S-phase entry was significantly decreased (Figure 1L). Next, we studied whether the MEC-1 cell line data were reproducible with primary CLL samples. CLL PBMCs were exposed to LDC526 for four hours and apoptosis was determined with Annexin V staining. Strikingly, significantly increased percentages of apoptosis were observed at concentrations of 500 and $1000 \mathrm{nM}$ (Figure 2A, 2B). Furthermore, increasing LDC526 concentrations led to significantly decreased MCL-1 protein levels while BCL-2 levels were not significantly altered (Figure 2C, 2D, 2E).

Subsequently, we investigated the in vitro cytotoxic impact of LDC526 on primary CLL cells (patient characteristics, Table 1) in comparison to healthy donor B cells after longer-term LDC526 exposure (Figure 2F). The 
A

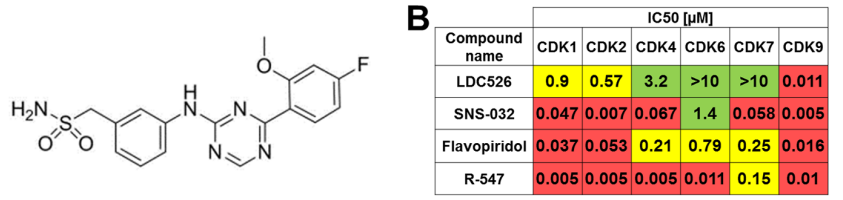

C
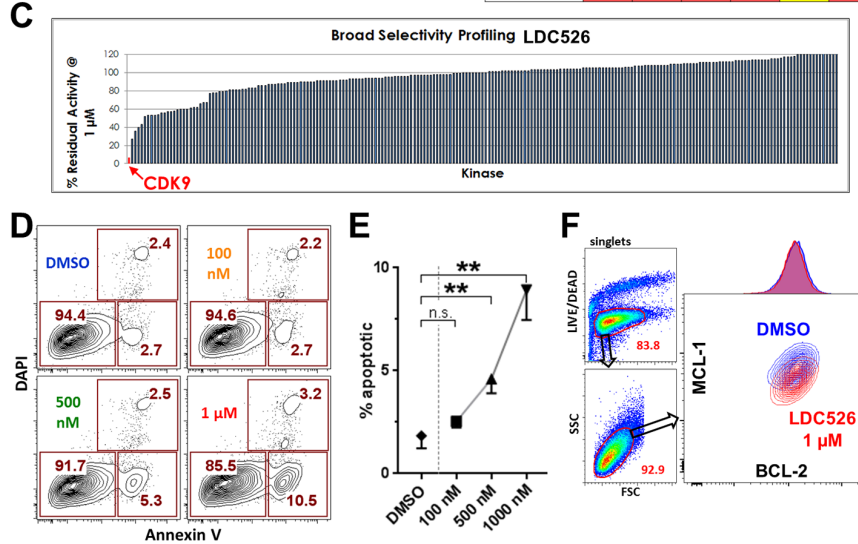

$\mathbf{F}_{\text {sing }}$

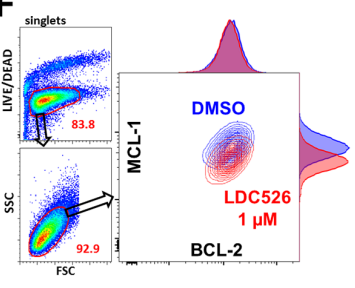

G
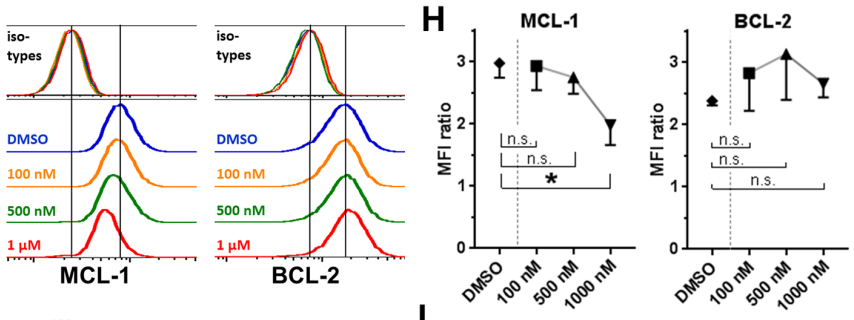

I
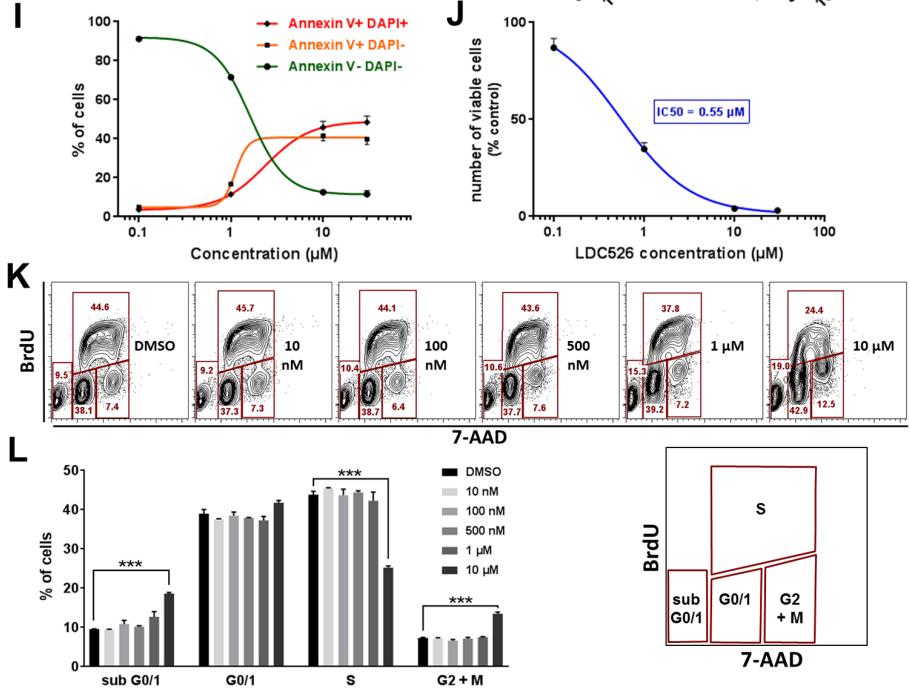

Figure 1: LDC526 is a potent CDK9 inhibitor inducing apoptosis of the MEC-1 cell line. (A) Molecular structure of LDC526. (B) Analysis of CDK family selectivity of LDC526 in comparison to other CDK inhibitors. Red: $\mathrm{IC}_{50}<0.1 \mu \mathrm{M}$; yellow: $\mathrm{IC}_{50} \geq 0.1$ and $<1 \mu \mathrm{M}$, green: $\mathrm{IC}_{50} \geq 1 \mu \mathrm{M}$. (C) High CDK9 specificity of LDC526 in a panel of 219 kinases. (D) Rapid induction of apoptosis by LDC526. Apoptosis was assessed by Annexin V and DAPI staining after 4 hours of LDC526 incubation. Representative plots are shown. (E) Quantification of apoptotic cells (Annexin V+, DAPI-; $n=3$ independent replicates; incubation for 4 hours). (F) Intracellular flow cytometric analysis of MCL-1 and BCL-2 expression within living (LIVE/DEAD dye negative) MEC-1 cells after 4 hours of LDC526 incubation. Overlay plots (DMSO and LDC626 $1 \mu \mathrm{M}$ ) with adjunct histograms are displayed. A representative plot is shown. (G) Representative histograms of intracellular MCL-1 and BCL-2 staining (with corresponding isotype controls) of MEC-1 cells after 4 hours of LDC626 incubation. (H) Quantification of intracellular MCL-1 and BCL-2 expression (MFI ratio: MFI anti-BCL-2 or anti-MCL-1/MFI corresponding isotype control antibody) after 4 hours of LDC626 incubation ( $\mathrm{n}=3$ independent replicates). (I) Increasing LDC526 concentrations decreased the proportion of viable (negativity for Annexin V and DAPI staining, determined by flow cytometry) and increased the proportions of apoptotic (Annexin V+, DAPI-) and dead (Annexin V+, DAPI+) MEC-1 cells ( $\mathrm{n}=4$ independent wells; 48 hours incubation). (J) LDC526 dose-response-curves depicting MEC-1 absolute viable cell numbers ( $\mathrm{n}=4$ independent wells; 48 hours incubation). (K) Representative plots of MEC-1 cell cycle analysis (flow cytometric BrdU cell cycle assay) after 24 hours of LDC526 incubation. (L) Quantification of MEC-1 cell cycle distribution after 24 hours of LDC526 incubation ( $\mathrm{n}=3$ independent replicates). ${ }^{*} \mathrm{p}<0.05 ;{ }^{* *} \mathrm{p}<0.01 ;{ }^{* * *} \mathrm{p}<0.001$. 

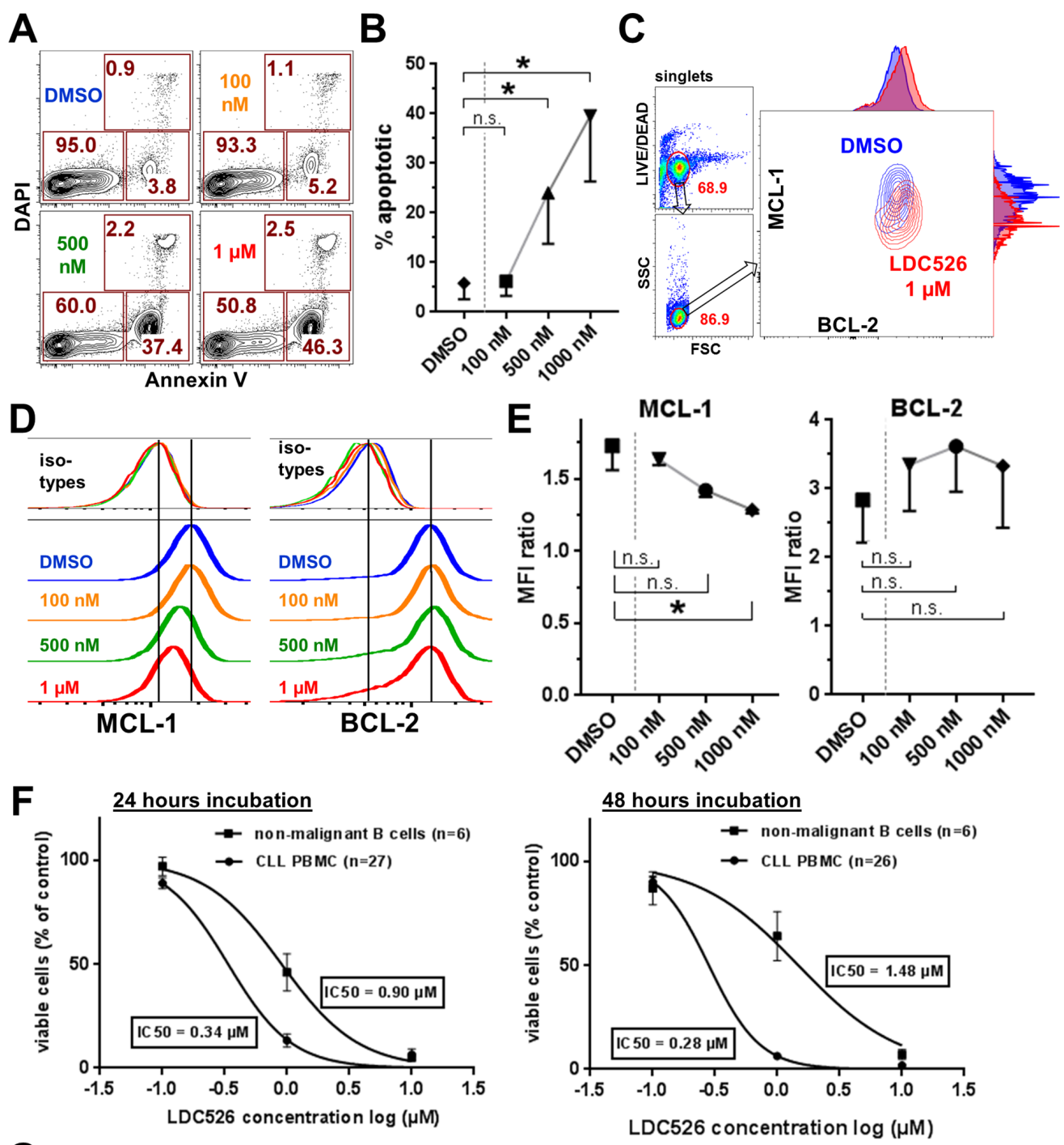

G

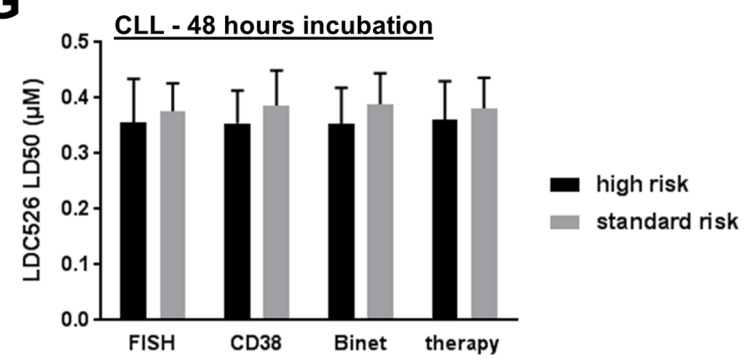

Figure 2: Antileukemic activity of LDC526 on primary CLL cells in vitro. (A) Induction of apoptosis in primary CLL cells by LDC526. Apoptosis was assessed by Annexin V and DAPI staining after 4 hours of LDC526 incubation. Plots of a representative analysis are shown. (B) Quantification of apoptotic cells (Annexin V+, DAPI-; n=4 CLL patients; 4 hours of incubation). (C) Representative intracellular flow cytometric analysis of MCL-1 and BCL-2 expression within living (LIVE/DEAD dye negative) CLL cells after 4 hours of LDC526 incubation. Overlay plots (DMSO and LDC626 $1 \mu \mathrm{M}$ ) with adjunct histograms are displayed. (D) Representative histograms of intracellular MCL-1 and BCL-2 staining (with corresponding isotype controls) of primary CLL cells after 4 hours of LDC526 incubation. (E) Quantification of intracellular MCL-1 and BCL-2 expression (MFI ratio: MFI anti-BCL-2 or anti-MCL-1/MFI corresponding isotype control antibody) after 4 hours of LDC526 incubation ( $\mathrm{n}=3$ CLL patients). (F) LDC526 dose-response curves showing the absolute number of viable CLL PBMCs (\% of DMSO control) and normal donor B cells determined with absolute cell counts and Annexin V/DAPI flow cytometric analysis. (G) LDC526-induced antileukemic effect within different prognostic CLL subgroups. High-risk: FISH, 11q or 17p deletion ( $n=10)$; CD38, proportion of CD38+ cells $\geq 30 \%(n=14)$; Binet, Binet B or C $(n=12)$; therapy, previous therapy ( $n=10)$. Low-risk: FISH low-risk, $(n=18)$; proportion of CD38+ cells $<30 \%,(n=14)$; Binet $A(n=16)$; no therapy $(n=18)$. Characteristics of the CLL patient cohort included in this study are outlined in Table 1 . Means \pm SEM are shown, no statistically significant differences between prognostic CLL subgroups ( $\mathrm{p}>0.05$ ) using Mann-Whitney-U test. 
Table 1: Patient characteristics

\begin{tabular}{|c|c|}
\hline Parameters & No. of patients $(\%)$ \\
\hline Total number of patients & $37(100)$ \\
\hline \multicolumn{2}{|c|}{ Mean age 64.6 years (range $43-80$ ) } \\
\hline female/male & $15 / 22(41 / 59)$ \\
\hline \multicolumn{2}{|l|}{ Binet stage $(n=37)$} \\
\hline A & $23(62)$ \\
\hline $\mathrm{B}$ & $5(14)$ \\
\hline $\mathrm{C}$ & $9(24)$ \\
\hline \multicolumn{2}{|l|}{ CD38 expression $(n=37)$} \\
\hline positive & $18(49)$ \\
\hline negative & $19(51)$ \\
\hline \multicolumn{2}{|c|}{ Genomic aberrations by FISH $(n=35)$} \\
\hline low-risk & $24(69)$ \\
\hline high-risk (deletion 11q or 17p) & $11(31)$ \\
\hline \multicolumn{2}{|l|}{ Treatment history $(n=37)$} \\
\hline treated & $13(35)$ \\
\hline untreated & $24(65)$ \\
\hline
\end{tabular}

number of viable (Annexin V-/DAPI-) CLL cells decreased with increasing LDC526 concentrations. Remarkably, normal donor B cells also displayed sensitivity towards LDC526. However, the $\mathrm{IC}_{50}$ of primary CLL cells was lower than the $\mathrm{IC}_{50}$ of non-malignant normal donor $\mathrm{B}$ cells. This difference in sensitivity was more pronounced at 48 hours than at 24 hours of incubation (Figure 2F). Finally, we analyzed whether prognostic CLL subgroups (Table 1) had a significant impact on LDC526-induced apoptosis. CLL patients were split into subgroups with respect to fluorescent in situ hybridization (FISH) genetic aberrations, CD38 surface expression, Binet stage and treatment history. In accordance with the assumption that even high-risk CLLs with e. g. p53 aberrations should be susceptible to the transcriptional elongation inhibition by LDC526 no statistically significant differences were observed between subgroups (Figure $2 \mathrm{G}$ ). Taken together, LDC526 displayed efficient cytotoxic activity against CLL cells in vitro. As expected, LDC526 decreased CLL MCL-1 protein levels and triggered apoptosis rather than inhibiting proliferation.

\section{LDC526 decreased human CLL numbers in CLL xenografted NSG mice}

In addition to the cytotoxic effect on CLL cells, selective CDK9 inhibition is likely to have pleiotropic effects in vivo. These include effects on the microenvironment of CLL cells comprising different cell types such as myeloid cells and T cells. Furthermore, proliferating activated CLL cells only exist in specific organ compartments such as lymph nodes, spleen and bone marrow. Therefore, we investigated the impact of specific pharmacologic CDK9 inhibition by LDC526 on CLL in vivo.

We and others previously established human CLL xenograft models using NOD/SCID and NSG mice, respectively [28-30]. We chose to use the NSG model for LDC526 experiments since NSG CLL and concomitant T cell engraftment levels are expected to be higher than in the NOD/SCID model [28-30]. We intravenously injected PBMCs from $n=6$ CLL patients into $n=57$ NSG mice and commenced LDC treatment with a 14 day latency 
according to the experimental set-up outlined in Figure $3 \mathrm{~A}$. To study the effect of doses and treatment duration we chose to administer 50 and $75 \mathrm{mg} / \mathrm{kg}$ for three days (NSG transplanted with cells originating from $n=3$ patients) and for five days (NSG transplanted with cells originating from $n=3$ additional patients). On experimental days 17 and 21 NSG spleens were harvested and the content of human CLL and T cells was determined by cell counting and flow cytometry (Figure 3B). The LDC526 impact on splenic NSG human CLL cell numbers was separately evaluated per originating CLL patient as engraftment was shown to vary between patients $[28,30]$. Compared to carrier control treatment, numbers of human CLL cells decreased after 3 and 5 days of LDC526 treatment, respectively. However, statistical significance regarding the reduction of human CLL cell numbers was only achieved at the LDC526 $75 \mathrm{mg} / \mathrm{kg}$ dose level (Figure 3C). In contrast, the numbers of splenic human $\mathrm{T}$ cells were significantly reduced at both LDC526 doses administered (Figure 3C). In order to determine whether there was differential in vivo LDC526 sensitivity of T cell subsets we performed additional staining for human CD4+ and CD8 + T cells present in the spleens of xenografted NSG mice (Figure 4A). The human CLL T cell compartment originating from $n=2$ CLL patients analyzed after 3 days LDC526 treatment exhibited a lower in one case and a constant CD4/CD8 ratio in the other case. In contrast, in mice transplanted with cells of $n=2$ other CLL patients and receiving LDC526 treatment for 5 days we observed a rising CD4/CD8 ratio with increasing LDC526 doses (Figure 4B). This could mean that CD8+ cytotoxic T cells are more susceptible to longer LDC526 exposure (5 versus 3 days) than CD4+ T cells. However, this differential skew within the $\mathrm{T}$ cell compartment could also reflect the heterogeneity of $\mathrm{T}$ cells derived from different CLL patients. On days 14-16 of the experimental plan (days 1-3 of LDC526 administration) mice did not show any signs of distress. A mean weight loss of $1.8 \%$ was detectable in mice of the LDC526 $75 \mathrm{mg} / \mathrm{kg}$ group (day 16). However, on the last day of the experiment (day 21) mice of the LDC526 $75 \mathrm{mg} / \mathrm{kg}$ dose group showed beginning signs of declined general condition with decreased general activity and the mean weight loss was 3.6\% (Supplementary Figure 1A). In conclusion, LDC526 displayed significant in vivo anti-human CLL activity. Remarkably, human $\mathrm{T}$ cell numbers were already decreased at a lower dose level than human CLL cells.

\section{LDC526 shows significant CLL cell cytotoxicity in TCL1 transgenic mice}

Another widely used preclinical CLL model are TCL1 transgenic mice [31]. The TCL1 transgenics represent a constitutive CLL model not involving the adoptive transfer of cells. This model mirrors the natural course of human $\operatorname{IgVH}$-unmutated CLL including its disease progression $[32,33]$. In addition, this model has also been widely used by others to test novel therapeutic molecules [34-36]. Hence, we used TCL1 transgenic mice to investigate the in vivo anti-CLL activity of LDC526. Consecutive blood sampling allowed us to carry out a longitudinal study in individual TCL1 and control mice. For this, we chose a cohort of TCL1 and littermate control mice, which were 9-12 months old (Figure 5A). We chose TCL1 transgenics with high peripheral CLL cell (CD19+CD5+) counts $(14.6 \pm 7.4 / \mathrm{nl}$, mean \pm SEM). Given the presumably high leukemic burden in these aged TCL1 mice and the reduced general condition of some NSG mice receiving 75 $\mathrm{mg} / \mathrm{kg}$ for 5 days we decided to dose TCL1 mice with 50 $\mathrm{mg} / \mathrm{kg}$ daily for two consecutive days (Figure $5 \mathrm{~A}$ ). As the experiment was longitudinally designed and there was no effect expected of administering carrier to wild-type control mice we omitted this control group and established three experimental groups (Figure 5A). In order to minimize stress by collecting blood specimens we sampled blood three times, 8 days apart (days $-5,+3$ and +11 ; Figure $5 \mathrm{~A}$ ). Compared to blood smears prepared before commencing LDC526 treatment a marked decrease of peripheral blood leukocytes and CLL cells was observed two days post the last LDC526 administration to TCL1 transgenic mice (Figure 5B). In contrast to the carrier control treated TCL1 mice, white blood cell counts (WBC) dropped in LDC526-treated wild-type and TCL1 mice (Figure 5C). In comparison to wild-type control mice, where WBC dropped to $34 \%$ of baseline values, the WBC decrease in TCL1 mice was more dramatic dropping to $8 \%$ of baseline values (Figure 5D). While hemoglobin counts did not change significantly (Figure 5E) platelet counts of LDC526treated mice were decreasing. In contrast to platelet counts of LDC526-treated wild-type mice, TCL1 platelet counts were even rising to significantly higher levels (day +11 ; $\mathrm{p}<0.01$ ) than measured at baseline (Figure 5F).

Peripheral blood CLL and non-malignant $\mathrm{T}$ and $\mathrm{B}$ lymphocyte subsets were defined by flow cytometry using antibodies against CD3, CD5 and CD19 (Figure 6A). Two days after the last LDC526 application TCL1 CLL cell concentrations decreased while CLL concentrations of TCL1 control mice did not change (Figure 6B). Peripheral blood CLL counts of individual LDC526-treated TCL1 mice decreased at least 8-fold (Supplementary Figure 2). Remarkably, mean TCL1 CLL numbers decreased 16-fold compared to baseline levels demonstrating a striking antileukemic effect of LDC526 (Figure 6C). In concordance with TCL1 CLL cells, TCL1 blood T cell concentrations also dropped (Figure 6D). Compared to the 16-fold decline of TCL1 CLL cells the decrease of T cells was not as dramatic (6-fold). However, in contrast to TCL1 T cells the concentration of wild-type T cells only halved by LDC526 treatment (Figure 6E).

We also determined the absolute non-malignant $B$ cell numbers within the peripheral blood. While nonmalignant $\mathrm{B}$ cell numbers of carrier control-treated 
A

huCLL ( $n=6$ patients) drug on days: 14-18

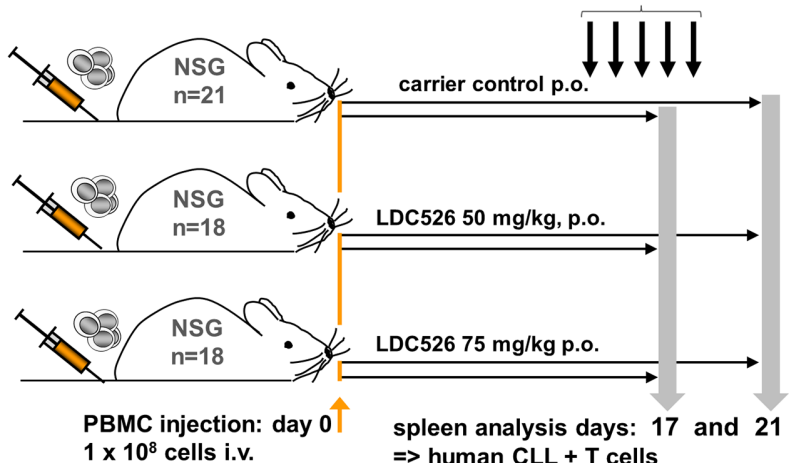

B
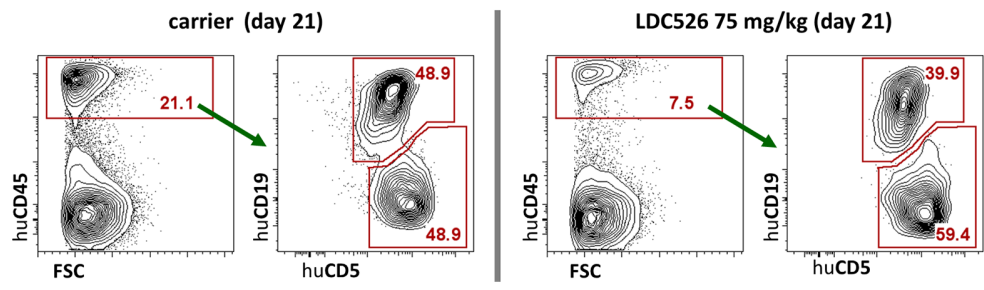

C
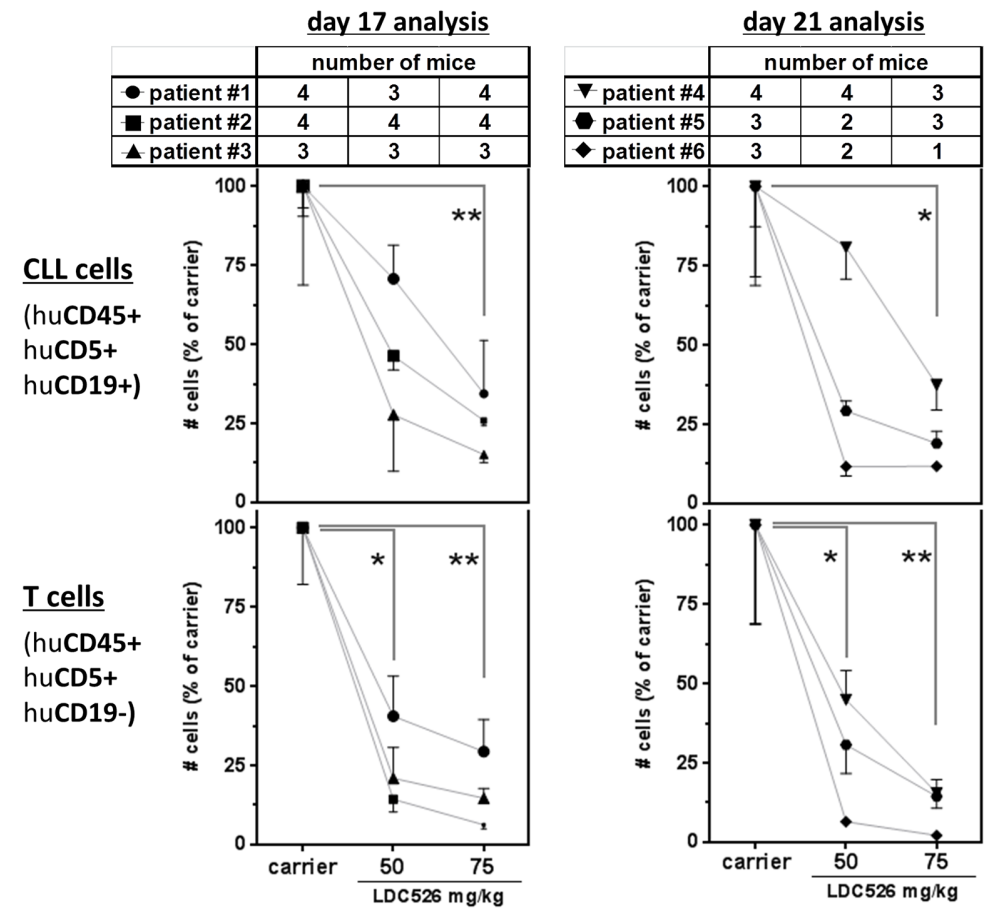

Figure 3: LDC526 decreases splenic human CLL numbers in xenografted NSG mice. (A) Scheme of the experimental set-up. CLL cells of individual patients were i.v. injected into n=3-4 NSG mice per treatment group (carrier control, LDC526 $50 \mathrm{mg} / \mathrm{kg}$ and $75 \mathrm{mg} /$ $\mathrm{kg}$ ). One cohort of NSG mice transplanted with cells from $\mathrm{n}=3$ individual CLL patients was analyzed on day 17. Another cohort of NSG mice transplanted with cells from $n=3$ further CLL patients was analyzed on day 21. (B) Representative flow cytometric analysis (day 21) of splenocytes of human CLL transplanted NSG mice treated with carrier or LDC526, respectively. (C) Quantification of splenic human CLL and splenic human T cells after carrier control and LDC526 treatment, respectively. Each data point represents the mean \pm SEM of NSG spleen cell numbers per individual CLL patient normalized to the mean cell numbers detected in spleens of corresponding carrier control treated mice (transplanted with the same leukemia). Mean CLL cell numbers were statistically compared in paired analyses. Tables depict the numbers of recipient NSG mice analyzed per data point. ${ }^{*} \mathrm{p}<0.05 ;{ }^{* *} \mathrm{p}<0.01$. 
TCL1 mice remained constant, LDC526 treatment led to a substantial decline of this lymphocyte population (Figure 6F). Non-malignant B cell numbers of LDC526treated TCL1 mice almost dropped by two log levels to $1.4 \%$ of baseline values (Figure $6 \mathrm{G}$ ). B cells of LDC526treated wild-type mice also dropped dramatically to $3.7 \%$ of baseline levels. As expected, weight loss of LDC526-treated TCL1 mice was more pronounced than the LDC526-induced weight-loss of wild-type mice. All but one LDC526-treated TCL1 mouse, which had to be euthanized due to reduced clinical condition on day +7 , regained their weight by day +8 (Supplementary Figure 1B). As the LDC526-associated weight loss was more severe in TCL1 transgenic mice than in wild-type control mice weight loss was at least in part associated with treatment response. In summary, LDC526 displayed an efficient cytotoxic effect against peripheral blood TCL1 CLL cells. Additionally, non-malignant $\mathrm{T}$ and $\mathrm{B}$ cell numbers also declined after LDC526 treatment.

On day +11 (Figure 5A) the experiment was terminated as planned and spleens of the experimental mice were harvested. To be able to assess the impact of LDC526 on wild-type spleens we included $n=3$ of non-treated age-matched wild-type littermate mice as an additional experimental control group in the final spleen analysis. A caveat of this final spleen analysis posed the fact that in contrast to the longitudinal blood analysis, baseline spleen data of individual aged TCL1 mice were not available. As longitudinal analysis was not possible, we now compared spleen parameters between cohorts. Importantly, it is unknown to which extent the amount of circulating peripheral blood TCL1 CLL cells determined at baseline correlates with splenomegaly. Nonetheless, TCL1 spleens of mice receiving LDC526 were macroscopically smaller than spleens of carriertreated TCL1 mice (Supplementary Figure 3A). Consistent with this, splenic weights of LDC-treated TCL mice were significantly lower than the splenic weights of TCL1 mice receiving carrier control treatment suggesting a therapeutic effect (Supplementary Figure 3B). There was also a trend $(p=0.09)$ towards a lower splenic absolute CLL cell content (Supplementary Figure 3C). Here, it has to be taken into account that LDC526 treatment was completed 10 days before the spleen analysis. Thus, as observed in the peripheral blood where CLL numbers increased again by $29 \%$ on day +11 compared to day +3 (Figure 6C) also splenic CLL cell numbers might have recovered during this period. In concordance with the peripheral
A

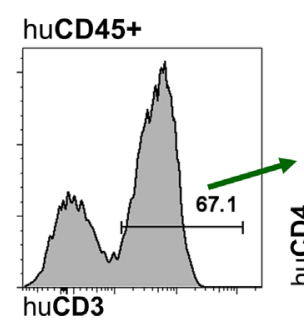

B

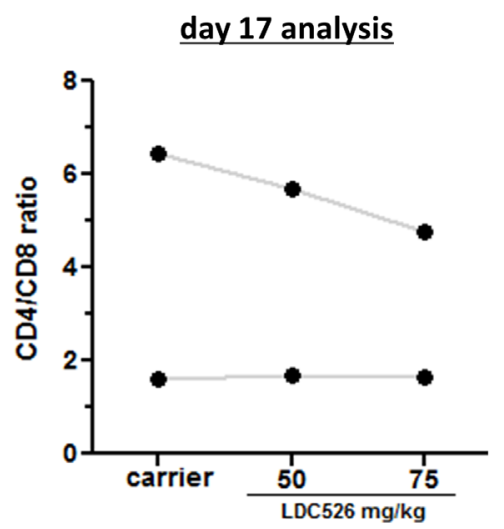

LDC526 $75 \mathrm{mg} / \mathrm{kg}$ (day 21)

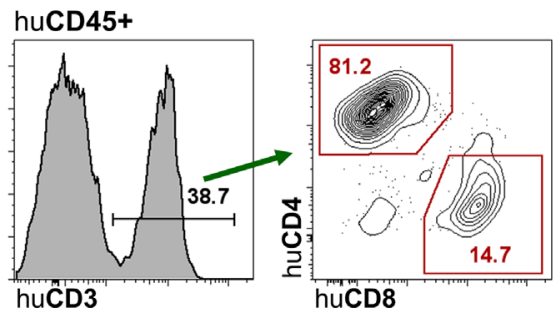

day 21 analysis

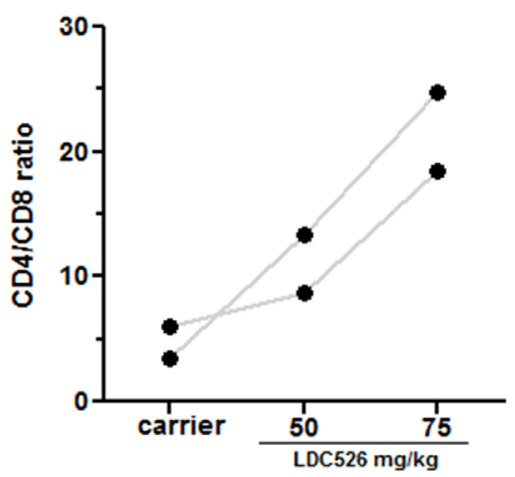

Figure 4: Analysis of human CD4+ and CD8+ T cell subsets in CLL transplanted NSG spleens. (A) Representative human $\mathrm{T}$ cell flow cytometric analysis (day 21) of spleens of human CLL transplanted NSG mice treated with carrier or LDC526 for 5 days, respectively (experimental scheme as outlined in Figure 3A). (B) CD4/CD8 ratios of residual human T cells in NSG spleens after LDC526 treatment were determined. Each data point represents the calculated mean CD4/CD8 ratio of residual T cells per individual CLL patient (day 17 analysis: $n=2$ patients; day 21 analysis: $n=2$ patients). 
blood data, TCL1 splenic T cells after LDC526 treatment were significantly decreased compared to TCL1 splenic $\mathrm{T}$ cells of carrier control treated mice (Supplementary Figure 3D). The LDC526 B cell cytotoxicity observed in the longitudinal blood analysis was also apparent when comparing absolute splenic B cell numbers of wild-type mice with and without LDC526 treatment (Supplementary Figure 3E). Taken together, spleens of LDC526-teated TCL1 mice were smaller than control TCL1 spleens implying a therapeutic benefit. The data also suggest that LDC526 treatment was capable of reducing TCL1 T cell numbers.

\section{Residual TCL1 CLL cells after LDC526 treatment exhibit high levels of Bcl-2}

Inhibition of CDK9 activity prevents RNA transcriptional elongation and deprives cells from the short-lived antiapoptotic protein MCL-1 leading to apoptosis [37]. Given the redundancy between the antiapoptotic proteins MCL-1 and BCL-2 we intended to study the effect of LDC526 on longitudinal cellular BCL-2 levels. We measured Bcl-2 protein levels in TCL1 lymphocyte subsets by flow cytometric analysis on days -5 and +3 (Figure $7 \mathrm{~A}$ ) of the experimental set-up outlined in

A

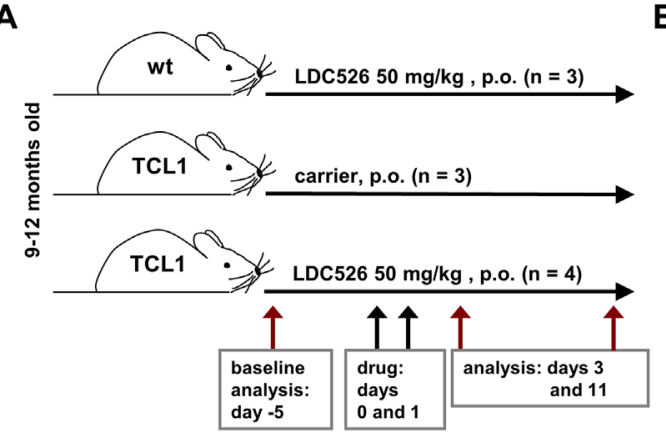

C

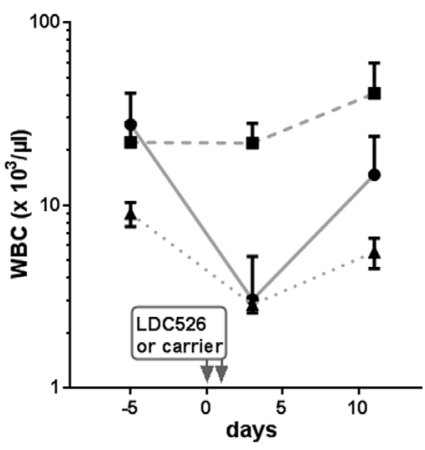

$\mathbf{E}$

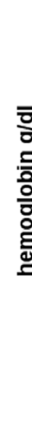

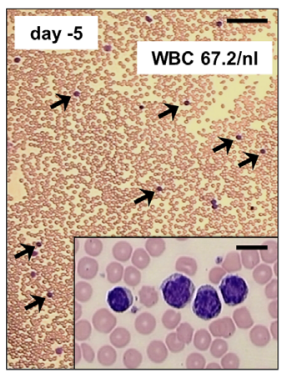

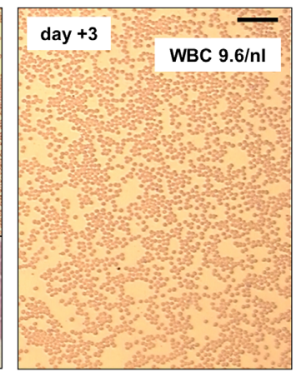

D
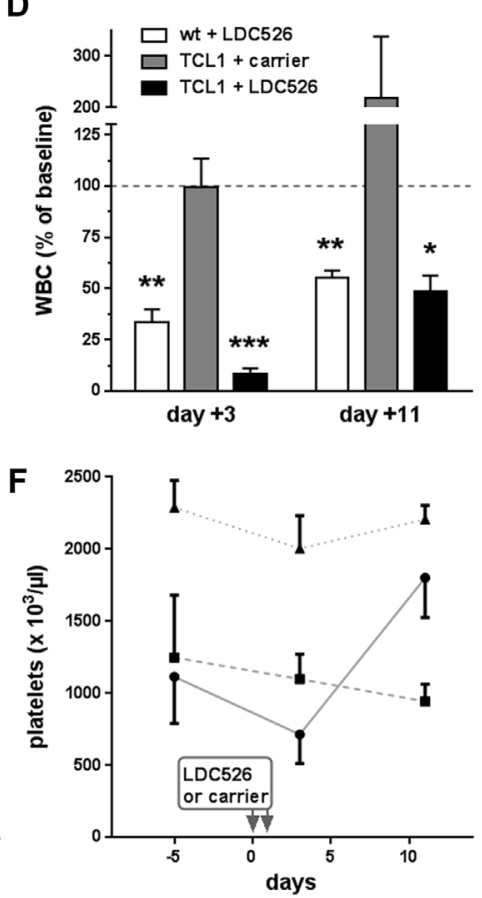

Figure 5: Peripheral blood count analysis of LDC526-treated TCL1 mice. (A) Scheme of the experimental set-up. (B) Sequential peripheral blood smears of a representative LDC526-treated TCL1 mouse. Arrows point at leukemic cells. Inset: Higher magnification of a group of leukemic cells. Images of baseline (day -5$)$ and day +3 smears are shown. Scale bar, $100 \mu \mathrm{M}$; inset scale bar $10 \mu \mathrm{m}$. (C) Longitudinal analysis of white blood cell counts (WBC). (D) Percent of WBC relating to baseline values (day -5). Longitudinal analysis of peripheral blood (E) hemoglobin and (F) platelet concentrations. ${ }^{*} \mathrm{p}<0.05 ;{ }^{* *} \mathrm{p}<0.01 ;{ }^{* * *} \mathrm{p}<0.001$ compared to baseline values. Means+/-SEM are shown. 
A

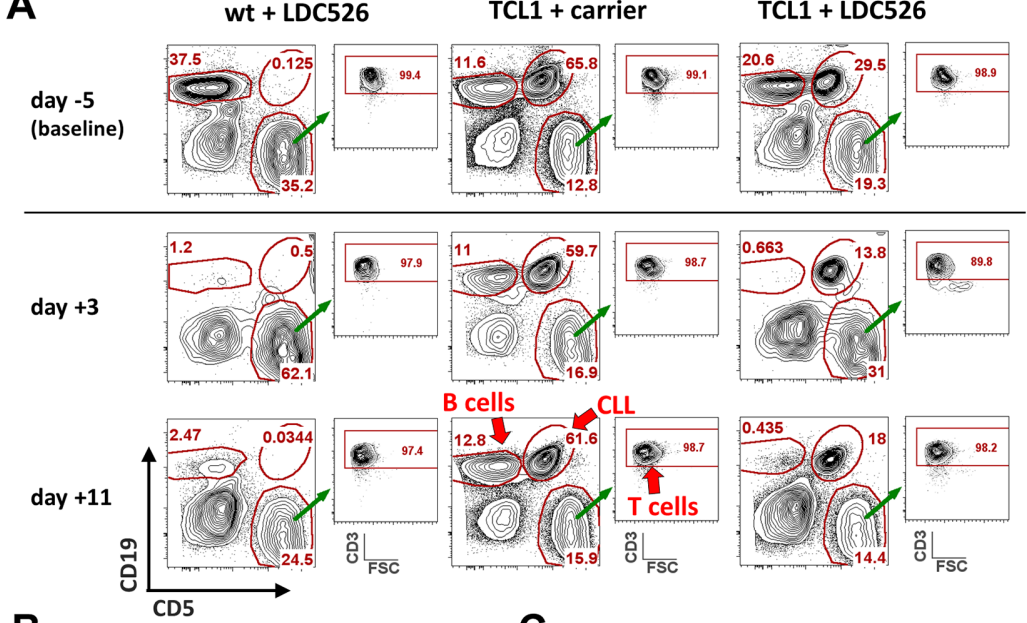

B
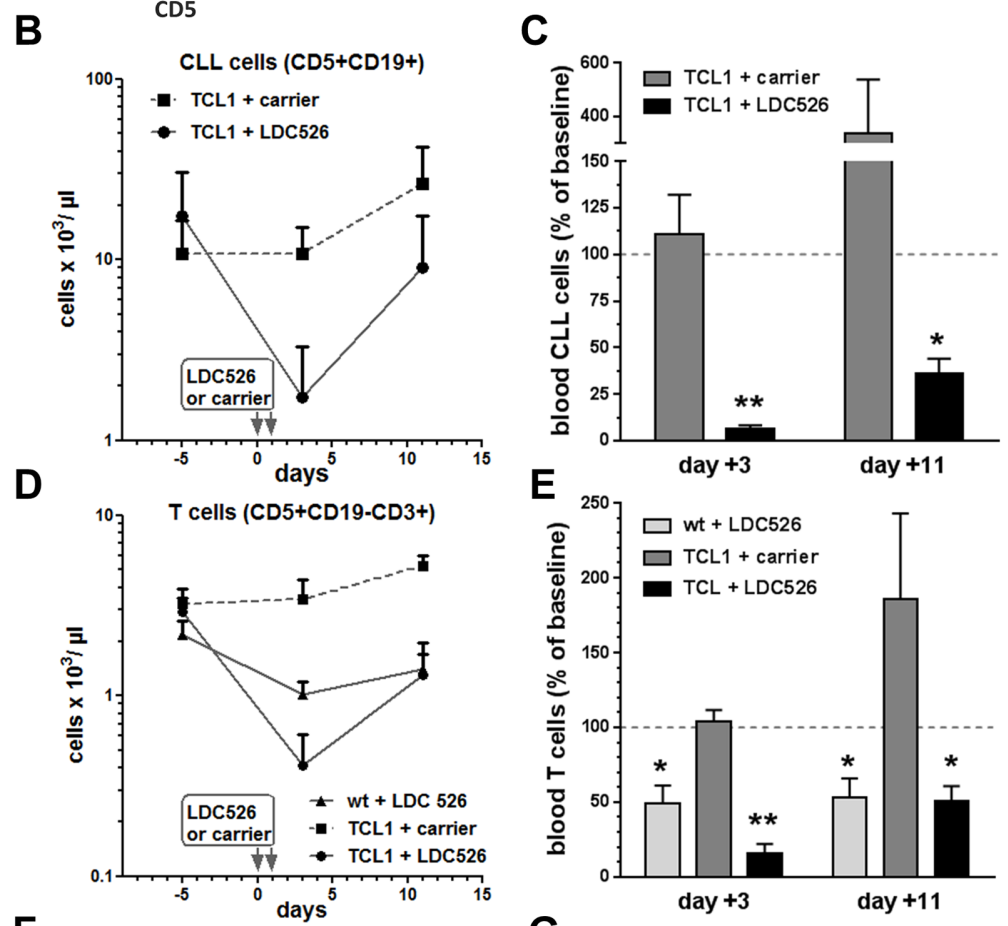

$\mathbf{F}$
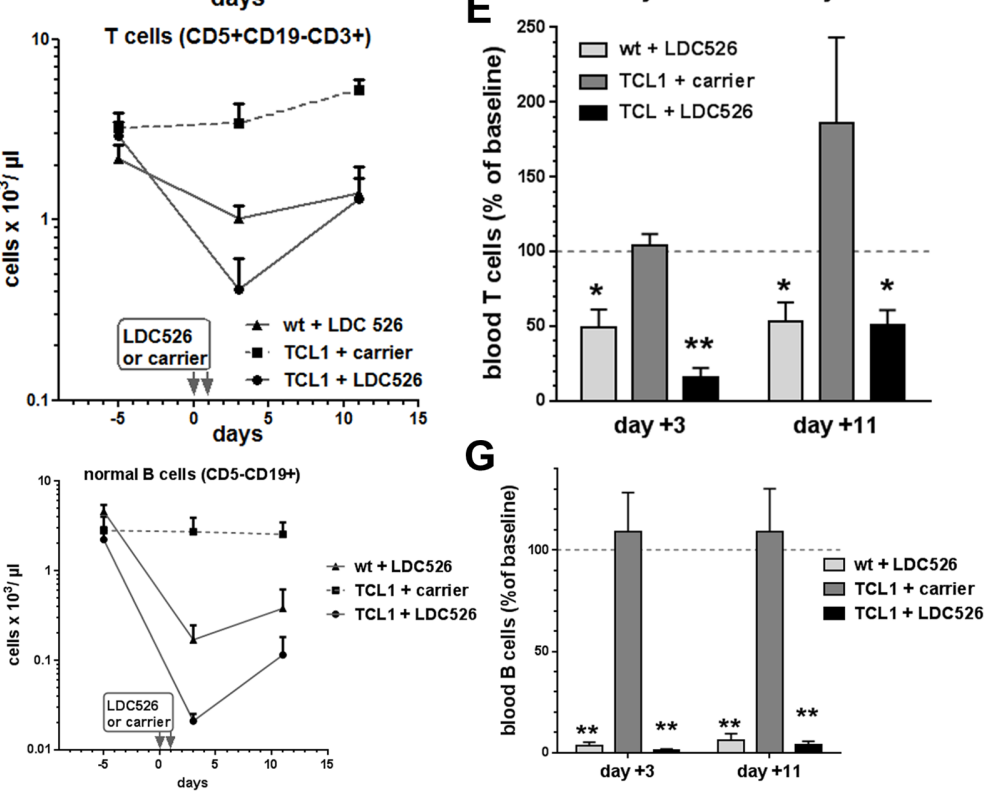

Figure 6: LDC526 treatment depletes peripheral blood CLL cells. (A) Representative flow cytometry plots of peripheral blood leukocytes (experimental scheme outlined in Figure 5A) stained with antibodies against CD5, CD19 and CD3 defining TCL1 CLL cells (CD5+CD19+), T cells (CD5+CD19-CD3+) and non-malignant B cells (CD5-CD19+), red arrows. By previous gating doublets (FSC-A vs. FSC-W) and dead cells (DAPI+) were excluded from the analysis. (B) Longitudinal quantification of circulating CLL cells. (C) Percent of CLL numbers relating to baseline values (day -5). (D) Longitudinal quantification of circulating T cells. (E) Percent of T cell numbers relating to baseline values (day -5). (F) Longitudinal quantification of non-malignant blood B cells. (G) Percent of non-malignant B cell numbers relating to baseline values (day -5$) .{ }^{*} \mathrm{p}<0.05 ;{ }^{* *} \mathrm{p}<0.01$. 
Figure 5A. As mentioned before, peripheral blood TCL1 CLL cells on day +3 were diminished to $6.4 \%$ of baseline levels by LDC526 treatment (Figure 6C). Remarkably, residual CLL cells exhibited significantly increased intracellular Bcl-2 levels after LDC526 exposure. Moreover, $\mathrm{T}$ cells that were decreased in numbers by LDC526 treatment also displayed significantly higher Bcl-2 levels compared to levels measured before LDC526 application (Figure 7B). We speculate that inherent higher cellular Bcl-2 levels of a subset of TCL1 CLL and T cells might have protected these cells from apoptosis by LDC526-mediated MCL-1 loss. Alternatively, LDC526 treatment might have induced upregulation of $\mathrm{Bcl}-2$ by a so far unknown mechanism in residual cells.

\section{DISCUSSION}

An increasing number of studies support the notion that pan-CDK inhibitors such as flavopiridol (Alvocidip) exert their primary anti-leukemic CLL activity by interfering with transcription via CDK9 inhibition rather than inhibiting the cell cycle [18, 38, 39]. Because panCDK inhibitors were associated with a narrow therapeutic window, it is anticipated that specific CDK9 inhibition would selectively inhibit transcription and not affect cell cycle progression and might therefore exhibit a more favorable safety profile. Compared to other CDK inhibitors such as flavopiridol and SNS-032 our novel CDK9 inhibitor LDC526 exhibited improved selectivity
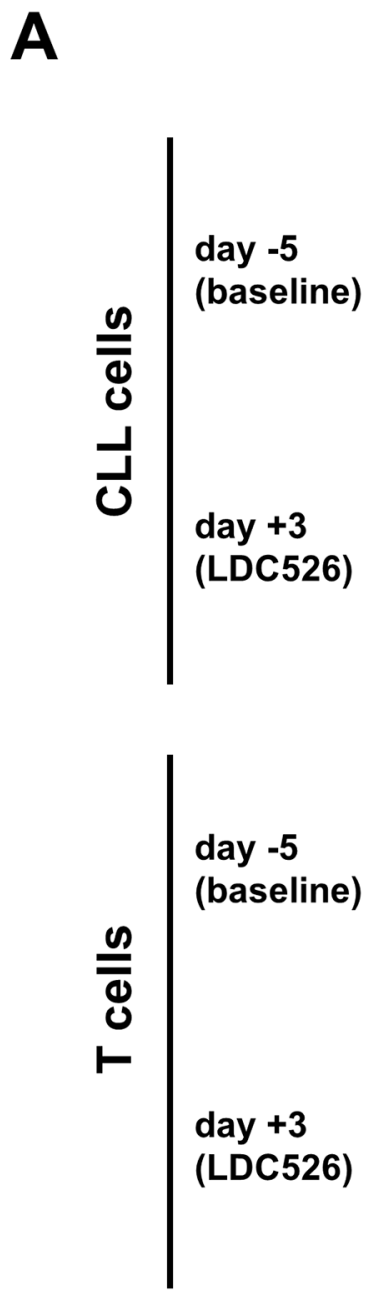

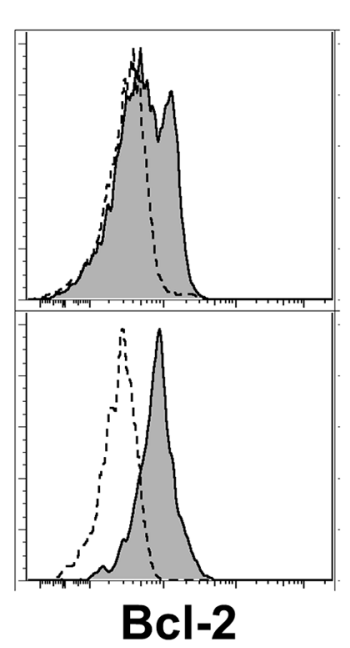

TCL1

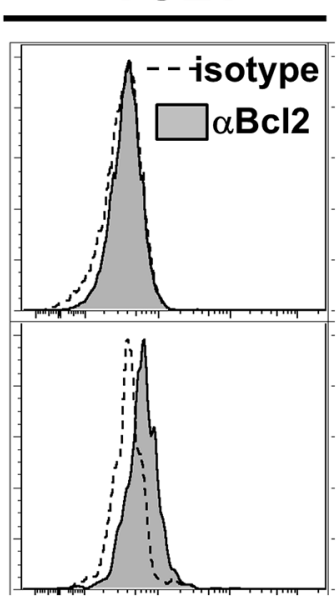

B
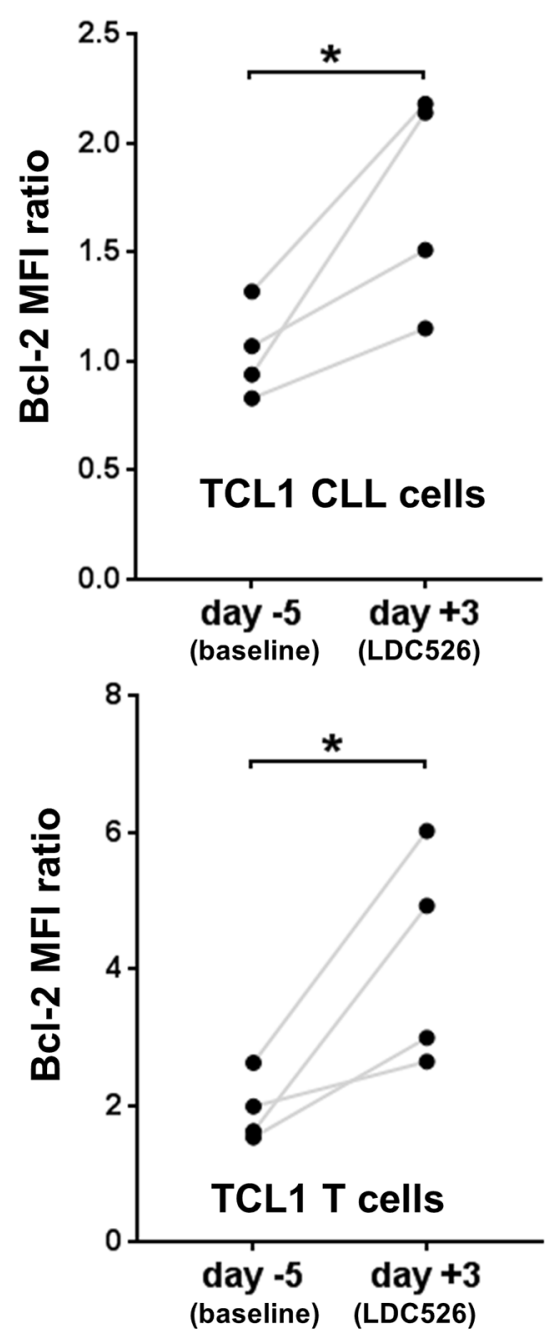

Figure 7: Residual CLL cells and T cells post LDC526 treatment express high levels of BCL-2. (A) Representative histograms of intracellular anti-Bcl-2 and corresponding isotype control staining of TCL1 CLL cells (CD5+CD19+) and T cells (CD5+CD19-). (B) Graphs comparing the CLL and $\mathrm{T}$ cell intracellular Bcl-2 expression of individual mice on days -5 and +3 . The Bcl-2 expression was quantified as median fluorescence intensity ratio (MFI ratio: MFI anti-Bcl-2/MFI isotype control antibody). ${ }^{*} \mathrm{p}<0.05$. 
for CDK9. Meanwhile, LDC526 was optimized further in terms of pharmacological parameters resulting in BAY1143572 [27], which has been studied in phase I trials in patients with acute leukemia and solid tumors / lymphomas (ClinicalTrials.gov, Identifier NCT02345382 and NCT01938638, respectively).

Here, we first studied the anti-CLL activity of LDC526 in vitro to provide the basis for subsequent in vivo studies carried out in the CLL NSG xenograft and the TCL1 transgenic CLL mouse model. Recently, other groups described other CDK9 inhibitors with improved CDK9 selectivity profiles such as CDKI-73 and LY2857585 [40-42]. The biochemical LY2857585 selectivity for CDK9 versus for example CDK7 was lower (22-fold;[42]) than the LDC526 CDK9 selectivity versus CDK7 (52-fold) described here. The degree of ex vivo CLL cell killing by LDC526 in the sub-micromolar range was comparable to the CLL cell killing achieved by LY2857585 and CDKI-73 [40-42].

Next, we moved on to in vivo testing of LDC526 in two independent mouse models of CLL. To our knowledge, there are only two other studies using the complementary CLL NSG xenograft and the TCL1 transgenic CLL mouse in preclinical drug testing $[43,44]$. This is the first study investigating the impact of a specific CDK9 inhibitor in CLL in vivo models. The use of in vivo models has the advantage of providing evidence whether the interaction of CLL and stroma influences the response to CDK9 inhibition. This is of particular importance since the interaction of CLL with stroma in vivo leads to increased CDK9 activity and elevated MCL-1 expression in CLL cells [45, 46]. Here, we demonstrated that LDC526 has dose-dependent in vivo anti-CLL activity in the NSG xenograft model. The insufficient LDC526 anti-CLL activity of the $50 \mathrm{mg} / \mathrm{kg}$ dose might well be explained by prevailing high stroma-induced expression levels of antiapoptotic proteins by CLL cells in the NSG spleen, which were not present in the in vitro setting.

In contrast to human CLL cells, the lower LDC526 $50 \mathrm{mg} / \mathrm{kg}$ dose was already capable of inducing significant anti-human $\mathrm{T}$ cell activity within the NSG spleen. Altogether, the LDC526 anti-human T cell activity appeared more pronounced than the anti-CLL activity in the NSG spleen environment. This might be due to fact that activated $\mathrm{T}$ cells involved in an alloreactive (in the case of NSG, xenoreactive) response were shown to be especially sensitive to CDK9 inhibition $[47,48]$. This is consistent with the upregulation of CDK9 upon $\mathrm{T}$ cell activation [49]. Since the proliferation of CLL cells was shown to be dependent on the presence of T cells in NSG spleens [29], the LDC526-mediated $\mathrm{T}$ cell reduction might have concomitantly contributed to the decreased splenic CLL cell numbers. However, it should be noted that residual $\mathrm{T}$ cells after 5 days of LDC526 therapy were primarily CD4+ T cells, which were shown to be indispensable for CLL proliferation in NSG spleens [29].
TCL1 mice mirror the course of human CLL as aged mice develop the clonal accumulation of CD5+CD19+ B cells in the blood and hematopoietic organs. Importantly, TCL1 mice display a response to CLL treatment analogous to human patients [32]. As disease onset and progression can be variable in TCL1 mice, we carried out a longitudinal study focusing on the course of peripheral blood CLL cell counts before and after LDC526 treatment. In parallel, we determined standard blood counts. In contrast to mean WBC dropping 12-fold in TCL1 mice after LDC526 treatment, mean platelet concentrations did not decrease below $50 \%$ of baseline levels. The decrease in platelet numbers was expected as $\mathrm{CDK} 9 / \mathrm{pTEFb}$ is involved in megakaryocyte maturation [50]. Possibly the platelet drop turned out relatively subtle because other CDKs involved in megakaryocyte differentiation and functions were not targeted by LDC526. Treating TCL1 mice with LDC526 resulted in a reduction of blood CLL cells to $6.4 \%$ of baseline values, which is a striking response for a twoday oral therapy. Comparability between the LDC526 CLL responses in TCL1 blood versus the NSG spleen is limited. Besides the species disparities between CLL cells studied, the difference observed in the magnitude of CLL response obtained in blood (TCL1) versus spleen (NSG) could be explained by the micro-environmental pro-survival signals CLL cells are exposed to in the NSG spleen which are not provided in the TCL1 circulation. In the NSG spleen pro-survival and proliferation signals are presumably delivered to human CLL cells within patientderived follicular structures that were described to be surrounded by human T cells [29].

Our study demonstrated in vivo cytotoxicity of non-malignant $\mathrm{T}$ cells towards specific CDK9 inhibition in the murine as well in the human CLL NSG system. Interestingly, TCL1 T cells exhibited a higher degree of LDC526 sensitivity than T cells of wild-type control mice without CLL. Others and we have shown skewing of the $\mathrm{T}$ cell compartment in CLL patients and in TCL1 mice towards an effector memory phenotype [51-53]. This might explain the higher LDC526 sensitivity of TCL1 CLL $\mathrm{T}$ cells compared to controls since the effector memory $\mathrm{T}$ cell subpopulations were shown to upregulate CDK9 and Cyclin T1 [49]. Moreover, LDC526 targeting of stromal non-malignant $\mathrm{T}$ cells exerting a CLL-supportive impact might have indirectly contributed to the LDC526 in vivo anti-CLL effect. On the other hand CD8+ T cells even though mainly dysfunctional in the CLL setting [51, $52,54]$ might still exert some anti-tumoral effects that would be depleted by LDC526 therapy. Furthermore, an increased rate of infectious complications due to decreased lymphocyte counts would be expected to emerge under LDC526 treatment.

Recently, direct in vivo cytotoxicity of the selective CDK9 inhibitor BAY1143572 against malignant T cells (adult $\mathrm{T}$ cell leukemia/lymphoma, ATL) was shown. BAY1143572 also exerted a cytotoxic effect against 
normal CD4+ T cells in vitro, which was not as prominent as the effect against ATL cells [27].

Remarkably, we demonstrated that LDC526 has a cytotoxic effect on non-malignant B cells in vivo. This effect involved normal B cells of diseased CLL TCL1 mice as well as circulating and splenic B cells of wild-type mice. LDC526 induced MCL-1 loss is likely responsible for the depletion of B cells since MCL-1 is required for the survival of most normal B cell subsets [55]. However, the LDC526-induced B cell loss was not complete since circulating $\mathrm{B}$ cell numbers were rising 10 days post the cessation of LDC526 treatment and splenic B cell numbers of LDC526-treated wild-type mice corresponded to 31\% of splenic B cell numbers of untreated mice.

We demonstrated in TCL1 CLL mice that residual CLL cells post LDC526 treatment exhibited higher Bcl2 levels than CLL cells before treatment. Interestingly, others described a similar upregulation of BCL-2 in CLL cells post $\mathrm{CDK}$ inhibitor exposure in vitro (24 hours) and patient treatment $\left(100 \mathrm{mg} / \mathrm{m}^{2}\right)$ with the pan-CDK inhibitor SNS-032 [18, 21]. The mechanism of how CDK9 inhibition might lead to higher cellular BCL-2 levels remains elusive. However, as transcription is suppressed by CDK9 inhibition upregulated BCL-2 mRNA expression appears an unlikely cause. Instead, CLL cells with a priori higher BCL-2 levels might exhibit a selective advantage to survive MCL-1 depletion by CDK9 inhibitor treatment. Remarkably, higher BCL-2 levels within lymphoma cells were shown to correlate with an increased sensitivity to venetoclax treatment [56]. Therefore, we think high BCL2 levels in residual CLL cells after CDK9 inhibitor therapy represent a rationale for combining CDK9 inhibitor treatment with a BCL-2 inhibitor such as venetoclax to achieve deeper CLL remissions or potentially cure. In line with this approach, CDK inhibition with flavopiridol or dinaciclib synergized with venetoclax to induce apoptosis of lymphoma cell lines in vitro $[57,58]$.

In conclusion, we describe the novel specific CDK9 inhibitor LDC526 and demonstrate effective LDC526 anti-leukemic activity in two independent preclinical CLL mouse models. Residual CLL cells after LDC526 treatment were characterized by higher BCL-2 levels. Therefore, specific CDK9 inhibitors are primary candidates for combination therapy with BCL-2-inhibitors to further deepen and prolong CLL treatment responses.

\section{MATERIALS AND METHODS}

\section{Cells and cell culture}

The MEC-1 cell line was obtained from the DSMZ (Braunschweig, Germany) and was cultured in RPMI (10\% fetal bovine serum). A LDC526 stock solution was prepared with DMSO, diluted and added to the cultures to reach the specified concentrations. Samples (percentage of CD19+CD5+CLL cells $>90 \%$ ) of $n=37$ CLL patients
(Table 1) and $n=6$ healthy normal donor controls were used for experiments after obtaining informed consent according to institutional guidelines, approved by the Ethics Commission of the University of Essen-Duisburg. Peripheral blood mononuclear cells (PBMC) were isolated using Lymphoprep (STEMCELL Technologies, Cologne, Germany) density gradient centrifugation and were used directly for NSG transplantation or in vitro experiments. Untouched normal donor B cells were isolated with a B cell isolation kit (Miltenyi, Bergisch Gladbach, Germany) according to the manufacturer's instructions. For in vitro experiments, cells were maintained in RPMI supplemented with $10 \%$ fetal bovine serum, penicillin and streptomycin.

\section{Mice}

All mice were bred and housed at the University Hospital Essen animal care facility. TCL1 mice [31] were back-crossed more than 6 generations into the C57BL/6 background and were genotyped as previously described [51]. Age-matched TCL1 wild-type littermates served as controls. Peripheral blood counts were determined with the VetABC analyzer (scil, Viernheim, Germany). Blood smears were Wright-Giemsa stained. For the human CLL xenograft experiments eight to 14-week-old NOD. Cg-Prkde ${ }^{\text {scid }}$ Il $2 \mathrm{rg}^{\text {tmlwjl }} / \mathrm{SzJ}$ (NOD/scid/ $/ \mathrm{c}^{\text {null. }}$;SG) mice were sublethally irradiated (3.25 Gy) 24 hours before transplantation. Freshly isolated $1.0 \times 10^{8} \mathrm{PBMC}$ suspended in $0.2 \mathrm{ml}$ of RPMI were intravenously transplanted as previously described [30]. For oral administration, LDC526 was diluted in polyethelene glycol (PEG $\mathrm{M}_{\mathrm{n}} 400$, SigmaAldrich) and administerd by gavage. Animal experiments were performed in accordance with institutional guidelines approved by the Animal Care Committee of the University Hospital Essen.

\section{Inhibitors}

LDC526 [(3-((4-(4-fluoro-2-methoxyphenyl)-1,3,5triazin-2-yl)amino)phenyl)methane-sulfonamide, molecular weight $389,41 \mathrm{~g} / \mathrm{mol}$, Figure $1 \mathrm{~A}$ ] was provided as powder (LDC526 synthesis, supplementary methods). For oral gavage administration LDC526 was diluted in polyethelene glycol (PEG M ${ }_{\mathrm{n}} 400$, Sigma-Aldrich, Munich, Germany) followed by sonication for $3 \times 5$ minutes with intermediate mixing. The CDK inhibitors SNS-032, R-547 (Selleckchem, Munich, Germany) and Flavopiridol (Sigma-Aldrich) were diluted in DMSO.

\section{In vitro enzymatic kinase assay for CDKs}

IC50 values for CDK inhibitors were determined using the fluorescence resonance energy transfer (FRET)based LANCE Ultra KinaSelect Ser/Thr kit (Perkin Elmer). Kinase activity and inhibition were measured according to the manufacturer's instructions and as previously described [59]. Briefly, a specific ULight 
MBP peptide substrate (50 $\mathrm{nM}$ final concentration) was allowed to get phosphorylated by a CDK-cyclin pair in enzymatic buffer (50 mM Hepes pH 7.5, $10 \mathrm{mM} \mathrm{MgCl2,}$ $1 \mathrm{mM}$ EGTA, $2 \mathrm{mM}$ dithiothreitol) containing ATP at the concentration of the $\mathrm{Km}$ values of the individual kinases for 1 hour at room temperature. Subsequently, phosporylation was detected by addition of specific europium (Eu)-labeled anti-phospho-antibodies (2 nM), which upon binding to the phospho-peptide give rise to a FRET signal. FRET signals were recorded in a timeresolved manner in a Perkin Elmer EnVision reader. Purified cyclin-kinase pairs were obtained from the following suppliers: Carna Biosciences (CDK1-Cyclin B1, CDK6-Cyclin D3, CDK7-Cyclin H-MAT1), ProQinase (CDK2-Cyclin A) and Invitrogen (CDK9-Cyclin T1). Broad selectivity kinase in vitro profiling with LDC526 was carried out using $n=219$ recombinant kinases (Millipore/Merck, Darmstadt, Germany).

\section{Cell preparation and flow cytometry}

Apoptosis and cell death were determined by using Annexin V (BD Biosciences, Heidelberg, Germany) and 4',6-Diamidin-2-phenylindol (DAPI, Sigma-Aldrich) staining. Erythrocytes of murine peripheral blood samples were lysed with $\mathrm{NH}_{4} \mathrm{Cl}$ hypotonic solution. Single cell suspensions of murine spleens were prepared as previously described [60]. Murine cells were stained with antibodies directed against murine CD3 (clone 145-2C11), CD5 (537.3) and CD19 (1D3), respectively. For the detection of human cells in NSG spleens antibodies against human CD3 (clone SK7), CD4 (SK3), CD5 (L17F12), CD8 (SK1), CD19 (J3-119 or SJ25C1) and CD45 (2D1) were used (purchased from BD Bioscience, Biolegend and Beckman Coulter). Flow cytometric analysis was carried out on a LSRII flow cytometer (BD Biosciences, Heidelberg, Germany). Flow cytometric data were analyzed with BD FACSDiva or FlowJo software (FLOWJO, LLC, Ashland, OR, USA). Intracellular staining for MCL-1 and BCL-2 (anti-MCL-1 [clone D2W9E, Cell Signaling Technology, Leiden, The Netherlands] and matched isotype control [clone DA1E, Cell Signaling Technology]; anti-BCL-2 [clone Bcl-2/100, $\mathrm{BD}$ Bioscience] and matched isotype control [clone MOPC21, BD Bioscience]) within MEC-1 and primary CLL cells was performed with the FoxP3 / Transcription factor staining buffer set (eBioscience/Thermo Fisher Scientific, Dreieich, Germany) according to the manufacturer's instructions. Before permeabilization and antibody incubation cells were stained with a fixable viability dye (eFluor 450, eBioscience/ Thermo Fisher Scientific). Before adding the anti-MCL-1 and anti-BCL-2 antibodies permeabilized cells were blocked with $2 \%$ mouse serum and $2 \%$ rabbit serum (SigmaAldrich) in permeabilization buffer. Intracellullar murine lymphocyte staining for Bcl-2 was carried out with the BD Cytofix/Cytoperm kit according to the manufacturer's instructions. A Hamster Anti-mouse Bcl-2 (clone 3F119,
BD Biosciences) and a corresponding isotype control (clone A19-3) were used. Dead cells and doublets were excluded by and FSC/SSC gating and positive DAPI or eFluor 450 viability dye staining, respectively. To assess the impact of LDC526 on the cell-cycle status of MEC-1 cells we used the BrdU Flow Kit according to the manufacturer's protocol (BD Bioscience). BrdU was added to the media 30 minutes before commencing the analysis.

\section{Imaging}

Macroscopic spleen images were taken with a Canon IXUS 1100 HS digital camera (Canon, Krefeld, Germany). Images of stained blood smears of LDC526 treated mice were taken through the 10x and 50x objective lenses of an Axioskope microscope (Zeiss, Jena, Germany).

\section{Statistical analyses}

Data were analyzed with GraphPad Prism 7 software. Differences were assessed by unpaired or paired Student $\mathrm{t}$ tests if not indicated otherwise. Two-sided probabilities of less than 0.05 were considered significant. Nonlinear regression sigmoidal dose-response curve fit was used to determine the $\mathrm{IC}_{50}$ values and to generate graphs. All data are displayed as mean \pm SEM.

\section{Abbreviations}

BCL-2, B-cell lymphoma/leukemia 2; BTK, Bruton's tyrosine kinase; CDK9, cyclin-dependent kinase 9; CLL, chronic lymphocytic leukemia; CTD, carboxyterminal domain; DAPI, 4',6-Diamidin-2phenylindol; FISH, fluorescent in situ hybridization; FRET, fluorescence resonance energy transfer; MCL1, Myeloid cell leukemia 1 (MCL-1); NSG, NOD/scid/ $\gamma \mathrm{c}^{\text {null }}$; PBMC, peripheral blood mononuclear cells; $\mathrm{PI} 3 \mathrm{~K} \delta$, phosphatidylinositol-3-kinase delta; RNAPII, RNA Polymerase II; pTEFb, transcription elongation factor $b$; WBC, White blood cell count.

\section{ACKNOWLEDGMENTS}

We thank the staff of the central animal facility (ZTL) of the University Hospital of Essen. We would like to thank Carlo Croce for his permission to use TCL1 transgenic mice.

\section{CONFLICTS OF INTEREST}

The authors declare no conflicts of interest.

\section{FUNDING}

JRG received grant support from the Stem Cell network of North-Rhine-Westphalia. The activities of the LDC have been co-funded by the Max-Planck Foundation, 
on behalf of the Max-Planck Society received, as well as by a grant from the Ministry for Research and Technology (BMBF), grant number 0315326.

\section{REFERENCES}

1. Siegel R, Naishadham D, Jemal A. Cancer statistics, 2013. CA Cancer J Clin. 2013; 63:11-30.

2. Eichhorst B, Hallek M. Prognostication of chronic lymphocytic leukemia in the era of new agents. Hematology (Am Soc Hematol Educ Program). 2016; 2016:149-55.

3. Buggins AG, Pepper CJ. The role of Bcl-2 family proteins in chronic lymphocytic leukaemia. Leuk Res. 2010; 34:837-42.

4. Lutzny G, Kocher T, Schmidt-Supprian M, Rudelius M, Klein-Hitpass L, Finch AJ, Dürig J, Wagner M, Haferlach C, Kohlmann A, Schnittger S, Seifert M, Wanninger S, et al. Protein kinase $c-\beta$-dependent activation of NF- $\kappa B$ in stromal cells is indispensable for the survival of chronic lymphocytic leukemia B cells in vivo. Cancer Cell. 2013; 23:77-92.

5. Burger JA, Gribben JG. The microenvironment in chronic lymphocytic leukemia (CLL) and other B cell malignancies: insight into disease biology and new targeted therapies. Semin Cancer Biol. 2014; 24:71-81.

6. Burger M, Hartmann T, Krome M, Rawluk J, Tamamura H, Fujii N, Kipps TJ, Burger JA. Small peptide inhibitors of the CXCR4 chemokine receptor (CD184) antagonize the activation, migration, and antiapoptotic responses of CXCL12 in chronic lymphocytic leukemia B cells. Blood. 2005; 106:1824-30.

7. Thompson PA, Tam CS, O'Brien SM, Wierda WG, Stingo F, Plunkett W, Smith SC, Kantarjian HM, Freireich EJ, Keating MJ. Fludarabine, cyclophosphamide, and rituximab treatment achieves long-term disease-free survival in IGHV-mutated chronic lymphocytic leukemia. Blood. 2016; 127:303-09.

8. Huber H, Edenhofer S, Estenfelder S, Stilgenbauer S. Profile of venetoclax and its potential in the context of treatment of relapsed or refractory chronic lymphocytic leukemia. Onco Targets Ther. 2017; 10:645-56.

9. Albitar A, Ma W, DeDios I, Estella J, Ahn I, Farooqui M, Wiestner A, Albitar M. Using high-sensitivity sequencing for the detection of mutations in BTK and PLC $\gamma 2$ genes in cellular and cell-free DNA and correlation with progression in patients treated with BTK inhibitors. Oncotarget. 2017; 8:17936-44. https://doi.org/10.18632/oncotarget.15316.

10. Choudhary GS, Al-Harbi S, Mazumder S, Hill BT, Smith MR, Bodo J, Hsi ED, Almasan A. MCL-1 and BCL-xLdependent resistance to the BCL-2 inhibitor ABT-199 can be overcome by preventing PI3K/AKT/mTOR activation in lymphoid malignancies. Cell Death Dis. 2015; 6:e1593.

11. Bodo J, Zhao X, Durkin L, Souers AJ, Phillips DC, Smith MR, Hsi ED. Acquired resistance to venetoclax (ABT-199) in $\mathrm{t}(14 ; 18)$ positive lymphoma cells. Oncotarget. 2016; 7:70000-10. https://doi.org/10.18632/oncotarget.12132.

12. Khaw SL, Mérino D, Anderson MA, Glaser SP, Bouillet P, Roberts AW, Huang DC. Both leukaemic and normal peripheral B lymphoid cells are highly sensitive to the selective pharmacological inhibition of prosurvival Bcl-2 with ABT-199. Leukemia. 2014; 28:1207-15.

13. Davids MS, Deng J, Wiestner A, Lannutti BJ, Wang L, Wu CJ, Wilson WH, Brown JR, Letai A. Decreased mitochondrial apoptotic priming underlies stroma-mediated treatment resistance in chronic lymphocytic leukemia. Blood. 2012; 120:3501-09.

14. Pepper C, Lin TT, Pratt G, Hewamana S, Brennan P, Hiller L, Hills R, Ward R, Starczynski J, Austen B, Hooper L, Stankovic T, Fegan C. Mcl-1 expression has in vitro and in vivo significance in chronic lymphocytic leukemia and is associated with other poor prognostic markers. Blood. 2008; 112:3807-17.

15. Yang T, Kozopas KM, Craig RW. The intracellular distribution and pattern of expression of Mcl-1 overlap with, but are not identical to, those of Bcl-2. J Cell Biol. $1995 ; 128: 1173-84$.

16. Lam LT, Pickeral OK, Peng AC, Rosenwald A, Hurt EM, Giltnane JM, Averett LM, Zhao H, Davis RE, Sathyamoorthy M, Wahl LM, Harris ED, Mikovits JA, et al. Genomic-scale measurement of mRNA turnover and the mechanisms of action of the anti-cancer drug flavopiridol. Genome Biol. 2001; 2:RESEARCH0041.

17. Yang T, Buchan HL, Townsend KJ, Craig RW. MCL-1, a member of the BLC-2 family, is induced rapidly in response to signals for cell differentiation or death, but not to signals for cell proliferation. J Cell Physiol. 1996; 166:523-36.

18. Chen R, Wierda WG, Chubb S, Hawtin RE, Fox JA, Keating MJ, Gandhi V, Plunkett W. Mechanism of action of SNS-032, a novel cyclin-dependent kinase inhibitor, in chronic lymphocytic leukemia. Blood. 2009; 113:4637-45.

19. Byrd JC, Shinn C, Waselenko JK, Fuchs EJ, Lehman TA, Nguyen PL, Flinn IW, Diehl LF, Sausville E, Grever MR. Flavopiridol induces apoptosis in chronic lymphocytic leukemia cells via activation of caspase-3 without evidence of bcl-2 modulation or dependence on functional p53. Blood. 1998; 92:3804-16.

20. Lanasa MC, Andritsos L, Brown JR, Gabrilove J, CaligarisCappio F, Ghia P, Larson RA, Kipps TJ, Leblond V, Milligan DW, Janssens A, Johnson AJ, Heerema NA, et al. Final results of EFC6663: a multicenter, international, phase 2 study of alvocidib for patients with fludarabinerefractory chronic lymphocytic leukemia. Leuk Res. 2015; 39:495-500.

21. Tong WG, Chen R, Plunkett W, Siegel D, Sinha R, Harvey RD, Badros AZ, Popplewell L, Coutre S, Fox JA, Mahadocon K, Chen T, Kegley P, et al. Phase I and pharmacologic study of SNS-032, a potent and selective $\mathrm{Cdk} 2,7$, and 9 inhibitor, in patients with advanced chronic 
lymphocytic leukemia and multiple myeloma. J Clin Oncol. 2010; 28:3015-22.

22. Byrd JC, Lin TS, Dalton JT, Wu D, Phelps MA, Fischer B, Moran M, Blum KA, Rovin B, Brooker-McEldowney M, Broering S, Schaaf LJ, Johnson AJ, et al. Flavopiridol administered using a pharmacologically derived schedule is associated with marked clinical efficacy in refractory, genetically high-risk chronic lymphocytic leukemia. Blood. 2007; 109:399-404.

23. Chen Y, Germano S, Clements C, Samuel J, Shelmani G, Jayne S, Dyer MJ, Macip S. Pro-survival signal inhibition by CDK inhibitor dinaciclib in Chronic Lymphocytic Leukaemia. Br J Haematol. 2016; 175:641-51.

24. Parry D, Guzi T, Shanahan F, Davis N, Prabhavalkar D, Wiswell D, Seghezzi W, Paruch K, Dwyer MP, Doll R, Nomeir A, Windsor W, Fischmann T, et al. Dinaciclib (SCH 727965), a novel and potent cyclin-dependent kinase inhibitor. Mol Cancer Ther. 2010; 9:2344-53.

25. Flynn J, Jones J, Johnson AJ, Andritsos L, Maddocks K, Jaglowski S, Hessler J, Grever MR, Im E, Zhou H, Zhu Y, Zhang D, Small K, et al. Dinaciclib is a novel cyclindependent kinase inhibitor with significant clinical activity in relapsed and refractory chronic lymphocytic leukemia. Leukemia. 2015; 29:1524-29.

26. Ghia P, Scarfò L, Perez S, Pathiraja K, Derosier M, Small K, McCrary Sisk C, Patton N. Efficacy and safety of dinaciclib vs ofatumumab in patients with relapsed/refractory chronic lymphocytic leukemia. Blood. 2017; 129:1876-78.

27. Narita T, Ishida T, Ito A, Masaki A, Kinoshita S, Suzuki S, Takino H, Yoshida T, Ri M, Kusumoto S, Komatsu H, Imada K, Tanaka Y, et al. Cyclin-dependent kinase 9 is a novel specific molecular target in adult T-cell leukemia/ lymphoma. Blood. 2017; 130:1114-24.

28. Herman SE, Sun X, McAuley EM, Hsieh MM, Pittaluga S, Raffeld M, Liu D, Keyvanfar K, Chapman CM, Chen J, Buggy JJ, Aue G, Tisdale JF, et al. Modeling tumor-host interactions of chronic lymphocytic leukemia in xenografted mice to study tumor biology and evaluate targeted therapy. Leukemia. 2013; 27:2311-21.

29. Bagnara D, Kaufman MS, Calissano C, Marsilio S, Patten PE, Simone R, Chum P, Yan XJ, Allen SL, Kolitz JE, Baskar S, Rader C, Mellstedt H, et al. A novel adoptive transfer model of chronic lymphocytic leukemia suggests a key role for T lymphocytes in the disease. Blood. 2011; 117:5463-72.

30. Dürig J, Ebeling P, Grabellus F, Sorg UR, Möllmann M, Schütt P, Göthert J, Sellmann L, Seeber S, Flasshove M, Dührsen U, Moritz T. A novel nonobese diabetic/ severe combined immunodeficient xenograft model for chronic lymphocytic leukemia reflects important clinical characteristics of the disease. Cancer Res. 2007; 67:8653-61.

31. Bichi R, Shinton SA, Martin ES, Koval A, Calin GA, Cesari R, Russo G, Hardy RR, Croce CM. Human chronic lymphocytic leukemia modeled in mouse by targeted TCL1 expression. Proc Natl Acad Sci USA. 2002; 99:6955-60.
32. Johnson AJ, Lucas DM, Muthusamy N, Smith LL, Edwards RB, De Lay MD, Croce CM, Grever MR, Byrd JC. Characterization of the TCL-1 transgenic mouse as a preclinical drug development tool for human chronic lymphocytic leukemia. Blood. 2006; 108:1334-38.

33. Yan XJ, Albesiano E, Zanesi N, Yancopoulos S, Sawyer A, Romano E, Petlickovski A, Efremov DG, Croce CM, Chiorazzi N. B cell receptors in TCL1 transgenic mice resemble those of aggressive, treatment-resistant human chronic lymphocytic leukemia. Proc Natl Acad Sci USA. 2006; 103:11713-18.

34. Woyach JA, Bojnik E, Ruppert AS, Stefanovski MR, Goettl VM, Smucker KA, Smith LL, Dubovsky JA, Towns WH, MacMurray J, Harrington BK, Davis ME, Gobessi S, et al. Bruton's tyrosine kinase (BTK) function is important to the development and expansion of chronic lymphocytic leukemia (CLL). Blood. 2014; 123:1207-13.

35. Merkel O, Wacht N, Sifft E, Melchardt T, Hamacher F, Kocher T, Denk U, Hofbauer JP, Egle A, Scheideler M, Schlederer M, Steurer M, Kenner L, Greil R. Actinomycin $\mathrm{D}$ induces $\mathrm{p} 53$-independent cell death and prolongs survival in high-risk chronic lymphocytic leukemia. Leukemia. 2012; 26:2508-16.

36. Suljagic M, Longo PG, Bennardo S, Perlas E, Leone G, Laurenti L, Efremov DG. The Syk inhibitor fostamatinib disodium (R788) inhibits tumor growth in the E $\mu$ - TCL1 transgenic mouse model of CLL by blocking antigendependent B-cell receptor signaling. Blood. 2010; 116:4894-905.

37. Morales F, Giordano A. Overview of CDK9 as a target in cancer research. Cell Cycle. 2016; 15:519-27.

38. Yeh YY, Chen R, Hessler J, Mahoney E, Lehman AM, Heerema NA, Grever MR, Plunkett W, Byrd JC, Johnson AJ. Up-regulation of CDK9 kinase activity and Mcl-1 stability contributes to the acquired resistance to cyclindependent kinase inhibitors in leukemia. Oncotarget. 2015; 6:2667-2679. https://doi.org/10.18632/oncotarget.2096.

39. Chen R, Keating MJ, Gandhi V, Plunkett W. Transcription inhibition by flavopiridol: mechanism of chronic lymphocytic leukemia cell death. Blood. 2005; 106:2513-19.

40. Liu X, Shi S, Lam F, Pepper C, Fischer PM, Wang S. CDKI71, a novel CDK9 inhibitor, is preferentially cytotoxic to cancer cells compared to flavopiridol. Int J Cancer. 2012; 130:1216-26.

41. Walsby E, Pratt G, Shao H, Abbas AY, Fischer PM, Bradshaw TD, Brennan P, Fegan C, Wang S, Pepper C. A novel Cdk9 inhibitor preferentially targets tumor cells and synergizes with fludarabine. Oncotarget. 2014; 5:375-85. https://doi.org/10.18632/oncotarget.1568.

42. Yin T, Lallena MJ, Kreklau EL, Fales KR, Carballares $\mathrm{S}$, Torrres R, Wishart GN, Ajamie RT, Cronier DM, Iversen PW, Meier TI, Foreman RT, Zeckner D, et al. A novel CDK9 inhibitor shows potent antitumor efficacy in 
preclinical hematologic tumor models. Mol Cancer Ther. 2014; 13:1442-56.

43. Yaktapour N, Übelhart R, Schüler J, Aumann K, Dierks C, Burger M, Pfeifer D, Jumaa H, Veelken H, Brummer T, Zirlik K. Insulin-like growth factor-1 receptor (IGF1R) as a novel target in chronic lymphocytic leukemia. Blood. 2013; 122:1621-33.

44. Herman SE, Montraveta A, Niemann CU, Mora-Jensen H, Gulrajani M, Krantz F, Mantel R, Smith LL, McClanahan F, Harrington BK, Colomer D, Covey T, Byrd JC, et al. The Bruton Tyrosine Kinase (BTK) Inhibitor Acalabrutinib Demonstrates Potent On-Target Effects and Efficacy in Two Mouse Models of Chronic Lymphocytic Leukemia. Clin Cancer Res. 2017; 23:2831-41.

45. Kurtova AV, Balakrishnan K, Chen R, Ding W, Schnabl S, Quiroga MP, Sivina M, Wierda WG, Estrov Z, Keating MJ, Shehata M, Jäger U, Gandhi V, et al. Diverse marrow stromal cells protect CLL cells from spontaneous and drug-induced apoptosis: development of a reliable and reproducible system to assess stromal cell adhesionmediated drug resistance. Blood. 2009; 114:4441-50.

46. Balakrishnan K, Burger JA, Fu M, Doifode T, Wierda WG, Gandhi V. Regulation of Mcl-1 expression in context to bone marrow stromal microenvironment in chronic lymphocytic leukemia. Neoplasia. 2014; 16:1036-46.

47. Li L, Wang H, Kim J, Pihan G, Boussiotis V. The cyclin dependent kinase inhibitor (R)-roscovitine prevents alloreactive $\mathrm{T}$ cell clonal expansion and protects against acute GvHD. Cell Cycle. 2009; 8:1794-802.

48. Zhan Y, Han Y, Sun H, Liang T, Zhang C, Song J, Hou G. Down-regulating cyclin-dependent kinase 9 of alloreactive CD4+ T cells prolongs allograft survival. Oncotarget. 2016; 7:24983-94. https://doi.org/10.18632/oncotarget.8804

49. Leucci E, De Falco G, Onnis A, Cerino G, Cocco M, Luzzi A, Crupi D, Tigli C, Bellan C, Tosi P, Leoncini L, Giordano A. The role of the Cdk9/Cyclin T1 complex in $\mathrm{T}$ cell differentiation. J Cell Physiol. 2007; 212:411-15.

50. Elagib KE, Rubinstein JD, Delehanty LL, Ngoh VS, Greer PA, Li S, Lee JK, Li Z, Orkin SH, Mihaylov IS, Goldfarb AN. Calpain 2 activation of $\mathrm{P}-\mathrm{TEFb}$ drives megakaryocyte morphogenesis and is disrupted by leukemogenic GATA1 mutation. Dev Cell. 2013; 27:607-20.

51. Göthert JR, Eisele L, Klein-Hitpass L, Weber S, Zesewitz ML, Sellmann L, Röth A, Pircher H, Dührsen U, Dürig J. Expanded CD8 $+\mathrm{T}$ cells of murine and human CLL are driven into a senescent KLRG1+ effector memory phenotype. Cancer Immunol Immunother. 2013; 62:1697-709.

52. Hofbauer JP, Heyder C, Denk U, Kocher T, Holler C, Trapin D, Asslaber D, Tinhofer I, Greil R, Egle A. Development of CLL in the TCL1 transgenic mouse model is associated with severe skewing of the T-cell compartment homologous to human CLL. Leukemia. 2011; 25:1452-58.

53. Tinhofer I, Weiss L, Gassner F, Rubenzer G, Holler C, Greil R. Difference in the relative distribution of CD4+ T-cell subsets in B-CLL with mutated and unmutated immunoglobulin (Ig) VH genes: implication for the course of disease. J Immunother. 2009; 32:302-09.

54. McClanahan F, Riches JC, Miller S, Day WP, Kotsiou E, Neuberg D, Croce CM, Capasso M, Gribben JG. Mechanisms of PD-L1/PD-1-mediated CD8 T-cell dysfunction in the context of aging-related immune

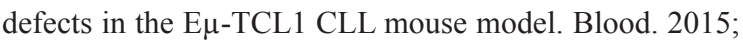
126:212-21.

55. Vikström IB, Slomp A, Carrington EM, Moesbergen LM, Chang C, Kelly GL, Glaser SP, Jansen JH, Leusen JH, Strasser A, Huang DC, Lew AM, Peperzak V, Tarlinton DM. MCL-1 is required throughout B-cell development and its loss sensitizes specific B-cell subsets to inhibition of BCL-2 or BCL-XL. Cell Death Dis. 2016; 7:e2345.

56. Souers AJ, Leverson JD, Boghaert ER, Ackler SL, Catron ND, Chen J, Dayton BD, Ding H, Enschede SH, Fairbrother WJ, Huang DC, Hymowitz SG, Jin S, et al. ABT-199, a potent and selective BCL-2 inhibitor, achieves antitumor activity while sparing platelets. Nat Med. 2013; 19:202-08.

57. Li L, Pongtornpipat P, Tiutan T, Kendrick SL, Park S, Persky DO, Rimsza LM, Puvvada SD, Schatz JH. Synergistic induction of apoptosis in high-risk DLBCL by BCL2 inhibition with ABT-199 combined with pharmacologic loss of MCL1. Leukemia. 2015; 29:1702-12.

58. Phillips DC, Xiao Y, Lam LT, Litvinovich E, RobertsRapp L, Souers AJ, Leverson JD. Loss in MCL-1 function sensitizes non-Hodgkin's lymphoma cell lines to the BCL2-selective inhibitor venetoclax (ABT-199). Blood Cancer J. 2016; 6:e403.

59. Albert TK, Rigault C, Eickhoff J, Baumgart K, Antrecht C, Klebl B, Mittler G, Meisterernst M. Characterization of molecular and cellular functions of the cyclin-dependent kinase CDK9 using a novel specific inhibitor. Br J Pharmacol. 2014; 171:55-68.

60. Sprüssel A, Schulte JH, Weber S, Necke M, Händschke K, Thor T, Pajtler KW, Schramm A, König K, Diehl L, Mestdagh P, Vandesompele J, Speleman F, et al. Lysinespecific demethylase 1 restricts hematopoietic progenitor proliferation and is essential for terminal differentiation. Leukemia. 2012; 26:2039-51. 